\title{
Upaya Meningkatkan Kualitas Layanan Publik Melalui Digitalisasi
}

\author{
Ani Yunaningsih ${ }^{1}$, Diani Indah ${ }^{2}$, Fajar Eryanto Septiawan ${ }^{3}$ \\ ${ }_{1,2,3}$ Universitas Langlangbuana, Indonesia \\ aniyunaningsih@gmail.com
}

\begin{abstract}
ABSTRAK
Pelayanan publik digital di era revolusi industry 4.0 merupakan suatu keniscayaan. Konsep layanan publik digital mengarah kepada prinsip efektis dan efisien. Efektif memiliki arti melaksanakan sesuatu yang tepat sedangkan efisien memiliki makna melaksanakan sesuatu dengan tepat. Pelayan publik digital diharapkan dapat memberikan kemudahan bagi siapa saja yang membutuhkan akses. Pelayanan publik digital ditandai dengan penggunaan media selain kertas atau yang sering disebut dengan paperless. Terknologi mempunyai peran penting agar peayanan publik digital dapat berjalan sebagaimana mestinya. Sekarang ini hampir semua orang bisa menjalankan atau mengoperasikan sebuah gawai, artinya kemudahan dapat dimiiki oleh setiap orang karena dapat mengakses informasi secara mudah melalui gawai yang dimiliki. Penelitian dilakukan secara deskriptif dan wawancara kepada pihak terkait untuk menemukan informasi terkait digitalisasi layanan publik. Hasil penelitian ditemukan bahwa teknologi dan informasi yang berkembang saat ini seperti artificial intelligent, mobile otonom, dan internet memberikan pengaruh yang sangat besar terhadap kehidupan manusia khususnya dalam hal cara berfikir dan cara bersikap. Layanan publik saat ini dituntut untuk bisa mengimbangi permintaan pengguna dalam hal ini warga. Semakin pahamnya pengguna terhadap teknologi berdampak pada keinginan pengguna unutuk mendapatkan layanan yang praktis, ekonomis, cepat dan tepat. Layanan pubik digital merupakan salah satu solusi untuk menjawab tantangan-tantangan tersebut.
\end{abstract}

Kata Kunci : Layanan Publik, Digitalisasi, Teknologi.

\begin{abstract}
Digital public service in the era of the industrial revolution 4.0 is a necessity. The concept of digital public services leads to effective and efficient principles. Adequate means are doing something right, while efficient means doing something appropriately. Digital public service is expected to provide convenience for anyone who needs access. Digital public service is characterized by the use of media other than paper or what is often referred to as paperless. Technology has an important role so that digital public services can run as they should. Nowadays, almost everyone can run or operate a device, meaning that everyone can have convenience because they can easily access information through their device. The research was conducted descriptively and interviews with related parties to find information related to the digitalization of public services. The study results found that the technology and information are currently developing, such as artificial intelligence, autonomous mobile, and the internet, have a very big influence on human life, especially in terms of how to think and behave. Public services are currently required to be able to balance user demands, in this case, citizens. The more familiarity of users with technology has an impact on the user's desire to get practical, economic, fast, and precise services. Digital public service is one solution to answer these challenges.
\end{abstract}

Keywords : Public Services, Digitalization, Technology.

Diterima : 18 Jan 2021, Direvisi: 1 Feb 2021, Dipublikasi: 15 Feb 2021 


\section{PENDAHULUAN}

Pelayanan publik digital di era revolusi industry 4.0 merupakan suatu keniscayaan. Konsep layanan publik digital mengarah kepada prinsip efektis dan efisien (Cabrilo et al., 2014). Efektif memiliki arti melaksanakan sesuatu yang tepat sedangkan efisien memiliki makna melaksanakan sesuatu dengan tepat (Almsalam, 2014; Gures et al., 2014; Utami, 2015). Pelayanan publik di tingkat yang paling bawah berada di tingkat RT dan RW sebagai ujung tombak penentu jalan tidaknya program pemerintah baik pusat maupun daerah. RW memiliki peranan yang sangat besar dalam tercapainya sasaran dan target program pemerintah karena RW yang paling mengetahui kondiai eksisting di lingkungan warganya.

Pelayan publik digital diharapkan dapat memberikan kemudahan bagi siapa saja yang membutuhkan akses (Fitriasari, 2020; Liu, 2012; Riyanto et al., 2018). Pelayanan publik digital ditandai dengan penggunaan media selain kertas atau yang sering disebut dengan paperless (Suma Vally \& Hema Divya, 2018). Terknologi mempunyai peran penting agar peayanan publik digital dapat berjalan sebagaimana mestinya. Sekarang ini hampir semua orang bisa menjalankan atau mengoperasikan sebuah gawai, artinya kemudahan dapat dimiiki oleh setiap orang karena dapat mengakses informasi secara mudah melalui gawai yang dimiliki (Aya Pastrana \& Sriramesh, 2014). Tantangan yang dihadapi dalam implementasi pelayanan publik digital harus dapat dihadapi dengan memiliki kompetensi manajerial dan kompetensi melayani. Kedua kompetensi tersebut apabila dikolaborasikan akan menciptkana kualitas layanan yang unggul. Kualitas layanan yang unggul tersebut dapat dicerminkan oleh kepuasan pengguna layanan dalam hal ini warga setempat (Laohasirichaikul \& Combs, n.d.; Soelasih, 2015).

Kelurahan Cikawao Kecamatan Lengkong Kota Bandung merupakan salah satu bagian di wilayah Kota Bandung dengan memiliki luas lahan sebesar 37,5 ha. Secara administratif Kelurahan Cikawao Kecamatan Lengkong Kota Bandung dibatasi oleh Bagian Selatan (Kecamatan Regol), Bagian Utara (Kelurahan Braga), Bagian Timur (Kelurahan Burangrang) dan Bagian Barat (Kecamatan Regol). Secara geografis Kelurahan Cikawao Kecamatan Lengkong Kota Bandung memiliki bentuk wilayah datar/berombak sebesar $98,5 \%$ dari total keseluruhan luas wilayah. Ditinjau dari sudut ketinggian tanah, Kelurahan Cikawao Kecamatan
Lengkong Kota Bandung berada pada ketinggian $700 \mathrm{~m}$ diatas permukaan air laut. Suhu maksimum dan minimum di Kelurahan Balonggede Kecamatan Regol Kota Bandung berkisar 20 $29^{\circ} \mathrm{c}$, sedangkan dilihat dari segi hujan berkisar $2400 \mathrm{~mm} / \mathrm{th}$ dan jumlah hari dengan curah hujan yang terbanyak sebesar 45 hari. Kelurahan Cikawao terdiri dari 9 Rukun Warga (RW) dan 55 Rukun Tetangga (RT). Jumlah penduduk pada tahun 2015 sebanyak 9.483 jiwa, terdiri dari 4.725 laki-laki dan 4.758 perempuan, sehingga kepadatan/Ha adalah 252,9 jiwa. Jumlah kepala keluarga sebanyak $1.778 \mathrm{KK}$, dengan kepadatan per KK sebanyak 5 orang. Mata pencaharian penduduk sebagai berikut: Pegawai Negeri Sipil (PNS) berjumlah 288 orang, ABRI/Polri sebanyak 129 orang, pegawai swasta berjumlah 788 orang, petani sebanyak 3 orang, dan pedagang sebanyak 1.211 orang.

Urusan administrasi kependudukan menjadi lebih mudah diakses melalui aplikasi formulir online. Keunggulan penggunaan aplikasi adalah lebih mudah diakses, efisiensi waktu, dan kepastian layanan serta meminimalisasi terjadinya pungli (pungutan liar) diluar biaya yang seharusnya dikeluarkan (Chiu et al., 2009; Kim \& Lennon, 2013; Sawitri et al., 2017). Permasalahan prioritas yang dihadapi oleh masyarakat RW 04 Kelurahan Cikawao antara lain:

1. Data kependudukan diinput secara manual dan konvensional, tidak ada tim khusus untuk pendataan penduduk.

2. Banyak program yang tidak dapat terrealisasi karena kurangnya sosialisasi.

3. Pelayanan administrasi terkadang membingungkan warga (berbelit-belit) hal ini dikarenakan warga tidak mengetahui standar operasional prosedur layanan.

4. Sampah masih dikelola secara konvensional belum ada nilai tambah.

Menelaah dari fenomena masalah pada Kelurahan Cikawao, maka terdapat kesempatan untuk mengkaji upaya digitalisasi layanan publik untuk meningkatkan kepercayaan masyarakat sebagai pengguna jasa.

\section{KAJIAN PUSTAKA Layanan Publik}

Pelayanan publik adalah kegiatan atau rangkaian kegiatan dalam rangka pemenuhan kebutuhan pelayanan sesuai dengan peraturan perundang-undangan bagi setiap warga Negara dan penduduk atas barang, jasa, dan/atau pelayanan administratif yang disediakan oleh penyelenggara pelayanan publik (Heiskala et al., 
2016; Vogt et al., 2013; Wise et al., 2012). setiap institusi penyelenggara Negara, korporasi, lembaga independen yang dibentuk berdasarkan undang-undang untuk kegiatan pelayanan publik, dan badan hukum lain yang dibentuk semata-mata untuk kegiatan pelayanan publik (Nasco \& Hale, 2009; Onofri \& Nunes, 2014). Kegitan tersebut dilaksanakan oleh pejabat, pegawai, petugas, dan setiap orang yang bekerja di dalam organisasi penyelenggara yang bertugas melaksanakan tindakan atau serangkaian tindakan pelayanan publik (Aziz et al., 2015).

Dalam pelaksanaan pelayanan publik harus berdasarkan standar pelayanan sebagai tolok ukur yang dipergunakan sebagai pedoman penyelenggaraan pelayanan dan acuan penilaian kualitas pelayanan sebagai kewajiban dan janji penyelenggara kepada masyarakat dalam rangka pelayanan yang berkualitas, cepat, mudah, terjangkau, dan terukur. Pelayanan publik diatur dalam Undang-Undang No. 25 Tahun 2009 Tentang Pelayanan Publik. Pengaturan ini dimaksu dan untuk memberikan kepastian hukum dalam hubungan antara masyarakat dan penyelenggara dalam pelayanan publik. Selain itu, pengaturan mengenai pelayanan publik bertujuan agar terwujudnya batasan dan hubungan yang jelas tentang hak, tanggung jawab, kewajiban, dan kewenangan seluruh pihak yang terkait dengan penyelenggaraan pelayanan publik (Richardson et al., 2013; Sawitri \& Febrian, 2018). Agar terwujudnya sistem penyelenggaraan pelayanan publik yang layak sesuai dengan asas-asas umum pemerintahan dan korporasi yang baik; agar terpenuhinya penyelenggaraan pelayanan publik sesuai dengan peraturan perundang-undangan; dan agar terwujudnya perlindungan dan kepastian hukum bagi masyarakat dalam penyelengaaran pelayanan publik (Mulyono et al., 2018; Riyanto et al., 2018).

Ruang lingkup pelayanan publik meliputi pelayanan barang publik dan jasa publik serta pelayanan administratif yang diatur dalam perundang-undangan (Beekman et al., 2014). Untuk menjamin kelancaran penyelenggaraan pelayanan publik diperlukan Pembina dan penanggung jawab. Pembina tersebut terdiri atas pimpinan lembaga Negara, pimpinan kementerian, pimpinan lembaga pemerintah non kementerian, pimpinan lembaga komisi Negara atau yang sejenis, dan pimpinan lembaga lainnya (Abdullah, 2020; Nugroho, 2011); gubernur pada tingkat provinsi; bupati pada tingkat kabupaten; dan walikota pada tingkat kota. Para Pembina tersebut mempunyai tugas melakukan pembinaan, pengawasan, dan evaluasi terhadap pelaksanaan tugas dari penanggung jawab (Sawitri \& Febrian, 2018). Sedangkan penanggung jawab adalah pimpinan kesekretariatan lembaga atau pejabat yang ditunjuk Pembina. Penanggung jawab mempunyai tugas untuk mengkoordinasikan kelancaran penyelenggaraan pelayanan publik sesuai dengan standar pelayanan pada setiap satuan kerja; melakukan evaluasi penyelenggaraan pelayanan publik; dan melaporkan kepada Pembina pelaksanaan penyelenggaraan pelayanan publik di seluruh satuan kerja unit pelayanan publik (Mulyono et al., 2018).

\section{Digitalisasi}

Digitisasi adalah proses mengubah sesuatu yang berbentuk non digital menjadi digital (Heiskala et al., 2016). Digitisasi dan digitalisasi sangat erat kaitannya. Keduanya sering dianggap sebagai istilah yang memiliki arti sama, tapi dalam praktiknya, keduanya memiliki arti yang berbeda (de Pablos Heredero \& Berzosa, 2011). Digitalisasi adalah proses membuat atau memperbaiki proses bisnis dengan menggunakan teknologi dan data digital. Istilah digitalisasi mengacu pada penggunaan teknologi dan data digital untuk meningkatkan bisnis, pendapatan, dan menciptakan budaya digital (Crawford et al., 2020; Johannessen \& Olsen, 2010). Dalam praktiknya, data digital dijadikan sebagai pendukung utama untuk seluruh proses tersebut. Jika sudah ditahap digitalisasi, perusahaan sudah mampu mengubah proses bisnis menjadi lebih efisien, produktif, dan menguntungkan (Hikmawati \& Alamsyah, 2018; Opute et al., 2020). Contoh praktiknya adalah mengunggah data atau informasi ke cloud dan membagikannya ke kolega agar dapat diakses dan dilihat secara bersamaan, lalu dianalisa untuk keperluan bisnis.

Transformasi digital adalah proses transformasi aktivitas, proses, dan model bisnis secara keseluruhan dengan memanfaatkan perkembangan teknologi (Fitriasari, 2020; Panourgias, 2015). Tujuan utamanya adalah meningkatkan efisiensi, mengelola risiko, dan menemukan peluang bisnis baru (Diaz-Rainey et al., 2015; Ramaswamy, 2009). Contoh praktiknya adalah menggunakan aplikasi atau sistem untuk menganalisa data. Tujuannya untuk mendapatkan insight baru yang berguna untuk pengembangan produk dan meningkatkan strategi layanan pelanggan (Crawford et al., 2020; Suma 
Vally \& Hema Divya, 2018). Proses ini tidak membutuhkan banyak interaksi manusia karena semuanya dilakukan secara otomatis oleh sistem. Hasilnya dapat meningkatkan efisiensi dalam hal waktu dan biaya, yang pada akhirnya juga dapat meningkatkan hasil penjualan (Alaeddin et al., 2018).

Digitisasi adalah proses mengubah informasi non-digital menjadi digital (Heiskala et al., 2016). Jika sebuah perusahaan menggunakan informasi digital tersebut untuk meningkatkan bisnis, menghasilkan pendapatan, atau menyederhanakan beberapa proses bisnis, maka itu disebut digitalisasi (Helm et al., 2019). Hasil dari proses digitisasi dan digitalisasi disebut transformasi digital. Digitisasi dan digitalisasi adalah tahap atau bagian dari proses menuju transformasi digital. Transformasi digital mencakup seluruh aspek dalam bisnis, dan penerapannya bukan hanya tentang memanfaatkan teknologi. Sumber daya manusia, teknologi, dan strategi bisnis saling bersinergi untuk menghasilkan bisnis yang lebih baik (Liu, 2012).

\section{METODOLOGI PENELITIAN}

Penelitian dilakukan dengan wawacara kepada responden yaitu masyarakat yang ada di Kelurahan Cikawao. Setelahnya dilakukan pelatihan terkait masalah yang dihadapi tentunya berkaitan dengan Digitalisasi. Metode pendekatan untuk memecahkan masalah yang ada di RW 04 Kelurahan Cikawao Kota Bandung Kecamatan Lengkong Kota Bandung, adalah sebagai berikut:

1. Pelatihan memasukan data ke big data dan menyimpan di cloud.

2. Pendampingan pengunaan media sosial sebagai sarana informasi publik.

3. Pelatihan pembuatan SOP digital.

4. Pembinaan pemilahan sampah.

\section{HASIL DAN PEMBAHASAN}

Rencana program pelaksanaan pengabdian masyarakat PKM Kelurahan Cikawao RW 04 seperti termuat dalam proposal, maka kegiatan pengabdian masyarakat ini dimulai dari kegiatan survei identifikasi masalah mitra, perumusan permasalahan, survei lapangan potensi yang ada sehingga bisa digunakan untuk memecahnkan masalah, menyiapkan tempat praktek dan pelatihan, pendampingan, praktek pelaksanaan program, evaluasi kegiatan dan pelaporan.

Pelaksanaan ini diikuti oleh ketua RT, ketua RW serta beberapa masyarakat RW 04 Kelurahan Cikawao Kecamatan Lengkong Kota Bandung dengan oleh tim PKM. Awal kegiatan yang dilakukan adalah mempersiapkan perangkat laptop/komputer serta membuat modul pelatihan dan praktek penggunakaan alat dengan menggunakan teknologi. Kemudian dilanjutkan dengan memberikan pelatihan cara pembuatan administrasi sederhana dengan computer/laptop lalu di upload ke cloud.

Selanjutnya untuk urusan sampah, ketua RT diberikan pengetahuan untuk diberitahukan kepada masyarakat untuk dapat memilah sampah yang nantinya akan memudahkan dalam pemanfaatan sampah. Masarakat sekitar juga diberi pengarahan oleh TIM PKM setiap bulannya untuk mendapatkan keahlian baru dalam mengelola sampah.

Program kemitraan masyarakat yang diadakan di RW 04 diharapkan dapat memperbaiki kualitas ayanan terhadap warga secara efektif dan efisien juga menignkatkan transparansi, control, dan akuntabilitas dalam rangka mewujudkan pelayanan prima. Era pandemik mewajibkan dikuranginya interaksi sosial maka dari itu digitalisasi merupakan solusi praktis untuk menjawab tantangan era revolusi industry 4.0 dimana pelayanan yang cepat dna pasti tanpa harus bertatap muka, biaya yang lebih murah juga menjadi pertimbangan serta dengan digitalisasi dapat menjangkau lebih luas lagi warga yang ingin mengakses. Menciptakan lingkungan masyarakat yang cepat dan tepat menyelesaikan masalah adalah destinasi dari program kemitraan masyarakat ini.

Digitalisasi ini merupakan suatu wujud implementasi dari PP nomor 71 tentang penyelenggaraan system elektronik dan PP nomor 96 tahun 2012 tentang pelayanan publik. Destinasi akhir dari PKM ini adalah terciptanya konsep smart environment dimana kebutuhan pelayanan dan admin kependudukan secara cepat, murah, inovatif. Keunggulan digitalisasi adalah daftar penduduk selallu terupdate serta paperless sebagai bentuk pelestarian lingkungan. Pengolahan sampah juga menjadi focus PKM ini, agar sampah yang tadinya adalah barang tidak berguna atau residu menjadi barang yang memiliki niai jual secara ekonomi maupun nilai manfaat

Jumlah warung makan, rumah makan, dan restoran di Kelurahan Cikawao sebagai berikut: 25 warung makan, 6 rumah makan, dan 1 restoran. Untuk sarana pariwisata dan rekreasi, terdapat 6 pub, 5 karaoke, dan 1 billiard. Sedangkan lembaga keuangan ada 9 bank umum, dan 1 koperasi. Kelurahan Cikawao berada di pusat kota Bandung tidak jauh dari Alun-alun Kota Bandung. Hal ini seharusnya menjadi suatu keungulan khususnya 
dalam hal pelayanan publik sebagai wilayah yang berada di tengah kota maka diharapkan pelayanan publik yang prima sudah menjadi suatu keniscayaan dan dapat direplikasi di tempat lain yang belum menjalankan pelayanan publik secara prima. Kelurahan Cikawai memiliki 9 RW di wilayahnya dengan berbagai macam karakteristik yang berbeda-beda. Lokus Program Kemitraan Masyarakat ini yaitu di RW 04 Melongkaler yang terletak tidak jauh dari Kantor Kelurahan Cikawao. RW 04 Melongkaler terdiri dari 6 RT dengan jumlah kepala keluarga kurang lebih 300 KK. Letak RW 04 cukup strategis karena berdekatan dengan kampus UNPAS Lengkong dan UNLA Karapitan. Terkait dengan letak RW 04 yang strategis tersebut maka menjadi destinasi dan tempat tinggal sementara bagi para mahasiswa yang kuliah di kampus tersebut. Fenomena itu ditandai dengan banyaknya rumah kos yang dibangun sehingga perbandingan antara warga dengan penduduk musiman bisa dikatakan lebih banyak penduduk musiman. Dampaknya adalah RW 04 enjadi lebih rawan akan tndak pencurian kendaraan bermotor karena antar sesama penghuni tidak saling mengenal. Volume sampah pun meningkat drastic ketika musim kuliah dimulai. Sampah yang menumpuk terkasang tidak dapat diangkut oleh petugas dikarenakan keterbatasan alat angkut kebersihan.

Melihat kondisi eksisting RW 04 maka perlu dilakukan pembenahan administrasi kependudukan melalui konsep digital yaitu mendata semua penduduk di lingkungan RW 04 baik penduduk tetap mau. Pun penduduk musiman yang dilakukan secara digital, yaitu data yang didapatkan di simpan pada big data secara cloud. Dengan adanya data yang akurat maka akan lebih mudah mengimplementasikan program-program yang telah di rencanakan. Warga juga lebih mudah mengakses informasi terkait program-program pemerintah baik pusat maupun daerah melalui aplikasi di dalam gawainya.

\section{KESIMPULAN DAN REKOMENDASI}

Tantangan yang dihadapi dalam implementasi pelayanan publik digital harus dapat dihadapi dengan memiliki kompetensi manajerial dan kompetensi melayani. Kedua kompetensi tersebut apabila dikolaborasikan akan menciptkana kualitas layanan yang unggul. Kualitas layanan yang unggul tersebut dapat dicerminkan oleh kepuasan pengguna layanan dalam hal ini warga setempat. Teknologi dan informasi yang berkembang saat ini seperti artificial intelligent, mobile otonom, dan internet memberikan pengaruh yang sangat besar terhadap kehidupan manusia khususnya dalam hal cara berfikir dan cara bersikap. Layanan publik saat ini dituntut untuk bisa mengimbangi permintaan pengguna dalam hal ini warga. Semakin pahamnya pengguna terhadap teknologi berdampak pada keinginan pengguna unutuk mendapatkan layanan yang praktis, ekonomis, cepat dan tepat. Layanan pubik digital merupakan salah satu solusi untuk menjawab tantangantantangan tersebut. Apalagi dunia sekarang ini sedang dilanda wabah corona, dimana sebagai bentuk pencegahan diharuskan untuk jaga jarak sosial dehingga interaksi antara penyedia layanan dengan pengguna layanan diharapkan tidak terlalu sering dilakukan dengan tatap muka. Kesimpulannya layan publik digital merupakan alternative yang baik sebagai salah satu langkah untuk tetap memberi layanan prima namun tetap memegang prinsip jaga jarak sosial.

\section{DAFTAR PUSTAKA}

Abdullah, I. (2020). COVID-19: Threat and Fear in Indonesia. Psychological Trauma: Theory, Research, Practice, and Policy, 12(5), $\quad$ 488-490. https://doi.org/10.1037/tra0000878

Alaeddin, O., Rana, A., Zainudin, Z., \& Kamarudin, F. (2018). From physical to digital: Investigating consumer behaviour of switching to mobile wallet. Polish Journal of Management Studies, 17(2), 18-30. https://doi.org/10.17512/pjms.2018.17.2.02

Almsalam, S. (2014). The Effects of Customer Expectation and Perceived Service Quality on Customer Satisfactio. International Journal of Business and Management Invention, 3(8), 79-84.

Aya Pastrana, N., \& Sriramesh, K. (2014). Corporate Social Responsibility: Perceptions and practices among SMEs in Colombia. Public Relations Review, 40(1), 14-24.

https://doi.org/10.1016/j.pubrev.2013.10.00 2

Aziz, M. A. A., Rahman, H. A., Alam, M. M., \& Said, J. (2015). Enhancement of the Accountability of Public Sectors through 
Integrity System, Internal Control System and Leadership Practices: A Review Study. Procedia Economics and Finance, 28(April), 163-169. https://doi.org/10.1016/s22125671(15)01096-5

Beekman, G., Bulte, E., \& Nillesen, E. (2014). Corruption, investments and contributions to public goods: Experimental evidence from rural Liberia. Journal of Public Economics, 115 , $37-47$. https://doi.org/10.1016/j.jpubeco.2014.04.0 04

Cabrilo, S., Nesic, L. G., \& Mitrovic, S. (2014). Study on human capital gaps for effective innovation strategies in the knowledge era. Journal of Intellectual Capital, 15(3), 411429. https://doi.org/10.1108/JIC-05-20140058

Chiu, C. M., Chang, C. C., Cheng, H. L., \& Fang, Y. H. (2009). Determinants of customer repurchase intention in online shopping. Online Information Review, 33(4), 761-784. https://doi.org/10.1108/1468452091098571 0

Crawford, J., Butler-Hunderson, K Rudolph, J., B., M., Glowatz, M., Burton, R., \& Lam, S. M. S. (2020). View of COVID-19: 20 countries' higher education intra-period digital pedagogy responses | Journal of Applied Learning and Teaching. Journal of Applied Learning \& Teaching3, (1)(1). https://journals.sfu.ca/jalt/index.php/jalt/arti cle/view/191/163

de Pablos Heredero, C., \& Berzosa, D. L. (2011). Open innovation in firms and public administrations: Technologies for value creation. In Open Innovation in Firms and Public Administrations: Technologies for Value Creation. https://doi.org/10.4018/978-1-61350-341-6

Diaz-Rainey, I., Ibikunle, G., \& Mention, A. L. (2015). The technological transformation of capital markets. Technological Forecasting and Social Change, 99, 277-284. https://doi.org/10.1016/j.techfore.2015.08.0 06

Fitriasari, F. (2020). How do Small and Medium- sized Enterprises (SME) survive the COVID-19 outbreak? Jurnal Inovasi Ekonomi, 5(3), 53-62. https://doi.org/10.22219/jiko.v5i3.11838

Gures, N., Arslan, S., \& Yucel Tun, S. (2014). Customer Expectation, Satisfaction and Loyalty Relationship in Turkish Airline Industry. International Journal of Marketing Studies, 6(1), 66-74. https://doi.org/10.5539/ijms.v6n1p66

Heiskala, M., Jokinen, J. P., \& Tinnilä, M. (2016). Crowdsensing-based transportation services - An analysis from business model and sustainability viewpoints. Research in Transportation Business and Management, 18, 38-48. https://doi.org/10.1016/j.rtbm.2016.03.006

Helm, S., Serido, J., Ahn, S. Y., Ligon, V., \& Shim, S. (2019). Materialist values, financial and pro-environmental behaviors, and wellbeing. Young Consumers. https://doi.org/10.1108/YC-10-2018-0867

Hikmawati, N. K., \& Alamsyah, D. P. (2018). The digital company based on competitive strategy. Proceedings of the 3rd International Conference on Informatics and Computing, ICIC 2018, 2001. https://doi.org/10.1109/IAC.2018.8780516

Johannessen, J. A., \& Olsen, B. (2010). The future of value creation and innovations: Aspects of a theory of value creation and innovation in a global knowledge economy. International Journal of Information Management, 30(6), 502-511.

https://doi.org/10.1016/j.ijinfomgt.2010.03. 007

Kim, J., \& Lennon, S. J. (2013). Effects of reputation and website quality on online consumers' emotion, perceived risk and purchase intention: Based on the stimulusorganism-response model. Journal of Research in Interactive Marketing, 7(1), 3356.

https://doi.org/10.1108/1750593131131673 4

Laohasirichaikul, B., \& Combs, H. (n.d.). Effective customer relationship management of health care: a study of hospitals in 
Thailand. 1-13.

Liu, C. (2012). The myth of informatization in rural areas: The case of China's Sichuan province. Government Information Quarterly, 29(1), 85-97. https://doi.org/10.1016/j.giq.2011.06.002

Mulyono, H., Indonesia, M., \& Helmi, S. (2018). $e-C R M$ and Loyalty: A Mediation Effect of Customer Experience and Satisfaction in Online Transportation of Indonesia e-CRM and Loyalty: A Mediation Effect of Customer Experience and Satisfaction in Online Transportation of Indonesia. September.

Nasco, S. A., \& Hale, D. (2009). Information search for home, medical, and financial services by mature consumers. Journal of Services Marketing, 23(4), 226-235. https://doi.org/10.1108/0887604091096556 6

Nugroho, Y. (2011). Opening the black box: The adoption of innovations in the voluntary sector-The case of Indonesian civil society organisations. Research Policy, 40(5), 761777.

https://doi.org/10.1016/j.respol.2011.03.002

Onofri, L., \& Nunes, P. A. L. D. (2014). De rationibus est disputandum: Psychological dimensions of choice and public policy design. Ecosystem Services, 10, 172-179. https://doi.org/10.1016/j.ecoser.2014.09.011

Opute, A. P., Irene, B. O., \& Iwu, C. G. (2020). Tourism service and digital technologies: A value creation perspective. African Journal of Hospitality, Tourism and Leisure, 9(2), 118.

Panourgias, N. S. (2015). Capital markets integration: A sociotechnical study of the development of a cross-border securities settlement system. Technological Forecasting and Social Change, 99, 317338.

https://doi.org/10.1016/j.techfore.2015.02.0 14

Ramaswamy, V. (2009). Leading the transformation to co-creation of value.
Strategy and Leadership, 37(2), 32-37. https://doi.org/10.1108/1087857091094120 8

Richardson, G., Taylor, G., \& Lanis, R. (2013). The impact of board of director oversight characteristics on corporate tax aggressiveness: An empirical analysis. Journal of Accounting and Public Policy, 32(3), 68-88. https://doi.org/10.1016/j.jaccpubpol.2013.0 2.004

Riyanto, A., Primiana, I., Yunizar, \& Azis, Y. (2018). Disruptive Technology: The Phenomenon of FinTech towards Conventional Banking in Indonesia. IOP Conference Series: Materials Science and Engineering, 407(1). https://doi.org/10.1088/1757899X/407/1/012104

Sawitri, N. N., \& Febrian, E. (2018). Determinants of demand for Islamic banking services: A survey on moslem public servants in Indonesia. Malaysian Journal of Consumer and Family Economics, 21(Special Issue 2), 65-73.

Sawitri, N. N., Oswari, T., \& Hastuti, E. (2017). Analysis of WebQual usefulness, information quality and interaction service in cultural sites online. International Journal of Economic Research, 14(6), 191-199.

Soelasih, Y. (2015). Is physical evidence still valid? A study of low cost carriers in Indonesia. Gadjah Mada International Journal of Business, 17(3), 203-218. https://doi.org/10.22146/gamaijb.8499

Suma Vally, K., \& Hema Divya, K. (2018). A study on digital payments and demonetization in India: Prospects and challenges. Journal of Advanced Research in Dynamical and Control Systems, $10(8$ Special Issue), 384-390.

Utami, S. (2015). The Influence of Customer Trust on Customer Loyalty. International Journal of Economics, Commerce and Management, III(7), 638-653.

Vogt, N., Reeson, A. F., \& Bizer, K. (2013). 
Communication, competition and social gift exchange in an auction for public good provision. Ecological Economics, 93, 11-19. https://doi.org/10.1016/j.ecolecon.2013.04.0 17

Wise, S., Paton, R. A., \& Gegenhuber, T. (2012). Value co-creation through collective intelligence in the public sector: A review of US and European initiatives. Vine, 42(2), 251-276.

https://doi.org/10.1108/0305572121122727 3 